\title{
MEASURING THE SECONDARY ECONOMIC IMPACT OF COVID-19 ON THE TOURISM INDUSTRY OF GEORGIA
}

\author{
GIORGI BREGADZE \\ PhD, Professor \\ Caucasus University, Georgia \\ g.bregadze@iset.ge
}

Abstract. Georgia experienced a substantial increase in the number of international visits during the last few years, boosting interest among the locals looking for new business opportunities. The optimistic expectations of future tourist flow led to an enormous amount of investments, mostly in the hospitality industry. The reality did not meet expectations after the world pandemic deteriorated the tourism flows leading to catastrophic losses for the tourism industry all over the world, including Georgia. This study employs a macroeconomics analysis tool - input-output model to identify the secondary economic effects of decreased tourism flows caused by COVID-19 in Georgia.

\section{KEYWORDS: ECONOMIC EFFECTS OF TOURISM, EFFECT OF COVID-19 ON TOURISM, INPUT-OUTPUT MODEL.}

For citation: Bregadze, G., (2021). Measuring the Secondary Economic Impact of Covid-19 on the Tourism Industry of Georgia. Globalization and Business. 12, 103-109. https://doi.org/10.35945/gb.2021.12.014

\section{INTRODUCTION}

Tourism is an umbrella industry comprising many production sectors of the country. Its economic influence became significant in Georgia and affected everyone, even those not directly involved in the tourism industry. International visits to Georgia reached a record number of 7,725,774 in 2019, out of which 5,080,478 were tourist visits. In the same year share of tourism in GDP increased to $7,8 \%$, while the international tourism receipt from the balance of payment reached 3.3 Bil. USD. The positive trend in the tourism industry changed in February of 2020 showing the first sign of the approaching catastrophe, which by the end of the year resulted in a decrease of $80.4 \%$ in international visits, $78.6 \%$ in tourist visits, and $82 \%$ in international travel receipts.

The policymakers usually steak to the above indicators when informing the public of the general effects of COVID-19. However, the mentioned indicators have little use for actual decision-making, as it shows just the partial picture. Over the last years, tourism researchers and policymakers have employed several macroeconomic analysis tools- international frameworks and models to estimate the economic impact of changed expenditure. A starting point for most tourism-related economic measures is the estimation of visitor expenditure, which by definition is the direct economic effect of tourism. Tourism expenditure is the amount paid for goods and services during tourism trips, which can be broken down by expenditure on accommodations, meals, shopping, and other categories.
It is important to distinguish between tourism expenditure (tourism Statistics) and international travel receipt (BoP), which are often confused by policymakers. Within the context of COVID-19, the differences between them are important because travel restrictions most likely affect the trips of visitors more than those of other types of travelers (UNWTO, 2021). There are two major differences between the concepts. The first difference is that the category "travel" includes the expenditures of travelers, who are not considered visitors (seasonal workers, long-term students, and patients staying in the country, etc.). The second difference is associated with the goods and services covered by the expenditure. The notion of "acquisition" used in the "travel" item is broader than the notion of visitor expenditure, including imputed values, such as the provision of accommodation free of charge. Purchases of valuables/consumer durables are included in visitor expenditure (irrespective of their unit value) whereas the "travel" item in the BoP includes only those purchases whose value is below the custom's threshold. This paper, therefore, concentrates on the concept of "tourism expenditure" (Nations, 2010).

To avoid differences between countries in the measurement of direct economic effects, a unique method, international framework tourism satellite account was created, which is consistent with a system of national accounts and comprises ten inter-related tables. Tables show the activities of visitors defined as "tourism", which is translated in different forms of tourism consumption in the country, its contribution to GDP, employment, and other macroeconomic variables 
(Nations, 2010); Bregadze, 2021) based on the experimental TSA tables 1-4 identified the most affected tourism sectors from Covid 19 based on three criteria structure of internal tourism expenditure, the share of internal expenditure in the total output and the share of domestic expenditure in internal expenditure. This paper extends the analysis of economic effects from Covid 19 on tourism by adding the secondary effects and employing the input-Output model for this purpose.

The secondary effects can be divided into indirect and induced effects. Indirect effects cover intermediate consumption for the production of goods and services in the tourism sector. For example, tourists spend money on hotel services, and to satisfy the demand, the hotel spends money on cleaning supplies, linens, and other materials. Tourism spending is the source of the wages and salaries of hotel employees. This income later is spent on different purposes: housing, food, entertainment, etc. This is the induced effect, which describes expenses incurred by employees with wages paid by companies in direct contact with tourists (Reece, 2010).

The process starting from the direct effect to the induced effect can be summarized in one concept multiplier effect. According to (Archer, 1982), the concept "multiplier" is used to measure the change in the final output, resulting from the initial change in visitor expenditure. The "multiplier" is the central and most important concept in tourism impact studies. The larger the value, the bigger is the effect of visitor expenditure on the economy. However, in times of pandemic, the effect is opposite as the larger value of multiplier leads to severe effects on the economy. While the high multiplier effect is desirable in times of flourished tourism, during the crisis it inflates negative consequences.

During the multiplier effect, the country loses some part of visitor expenditure, mainly because of imported goods and services. The same process takes place during the induced effects as well, when the population saves tourism-related income. This process is the leakage effect. WTO (1994) identified six import expenditure categories, which are the main sources of leakage: import of materials for construction, import of short-term consumption goods (e.g. food and beverage), repatriation of income from the foreigners, repatriation of profit from the foreigners, commissions on foreign debts, and marketing expenditures outside the country. The leakage is one of the fundamental problems for developing countries like Georgia. With several other problems, we can name the deficient economic structure as the primary reason for the leakage. The economy of Georgia is characterized by limited economic diversification, local industries are not capable to satisfy increased tourism consumption, and there is a lack of capital among the locals for investment. Those problems lead to a large number of imports and the need for foreign investments, which translates into a large leakage effect. Because of different definitions of leakage and methods of measurement, it is impossible to compare the indicator among the different countries. However, based on six different factors, the world tourism organization estimates the leakage effect in small island developing countries ranging from $40 \%$ to $50 \%$, while for larger and more diversified economies less than $10 \%$ (WTO, 1994). Although in peaceful times high import share suggests the high leakage and smaller multiplier effect, during COVID-19 times that translates into the lower negative effect on the local economy as the major losers, in that case, are from outside the country. The import dependency of developing countries seems to decrease the negative effect of COVID-19 on the local economy.

Researchers use the Input-Output Model, Social Accounting Matrix (SAM), or Computable General Equilibrium model to estimate secondary economic effects of tourism expenditure.

\section{Overview of the Economic Impact Models}

The policymakers often neglect the secondary effects of tourism not only during the crisis period but in peaceful times. While in peaceful times this neglect leads to an underestimation of the benefits of tourism, in crisis periods it translates in failing to understand the total economic damage.

The Input-Output model was first introduced by Leontief in 1940, receiving a Nobel Prize for this accomplishment in 1973. Isard and Kuenne (1953) were the first to use the model for the economic effect analysis, while (Archer, 1982) pioneered the exposition of I-O multipliers for tourism analysis. The Social Accounting Matrix (SAM) extends I-O modeling, showing more transactions in the national economy in greater detail.

After so many years, the Input-Output model is still popular among researchers and policymakers. The major advantage of the model is its method and availability of the data. SNA 2008 describes all the details of the method, while relevant authorities publish data used for modeling (supply and use table) regularly.

The Input-Output model describes the income flow between different industries. These flows show the requirements of each industry from other industries to produce one gel worth good. The input-output table is the basis of the model, showing the economy in the matrix form. The strength of the model is in its capability to analyze direct, indirect, and induced effects of tourism expenditure on indicators of different economic sectors. I-O model has the following functional form:

$\mathbf{A X}+\mathbf{Y}=\mathbf{X}, \mathbf{0}<\mathbf{A}<\mathbf{1}$ (Intermediate Consumption + Final Demand $=$ Total Output)

After some basic mathematical calculations, we receive the following final function:

$(\mathbf{I}-\mathbf{A})^{-1} \Delta \mathbf{Y}=\Delta \mathbf{X} \quad \mathbf{0}<\mathbf{A}<\mathbf{1} \quad$ (Leontief inverse matrix multiplied by the change in final demand leads to the change in total output)

The goal of the model is to calculate the Leontief inverse matrix, which shows inter-industry transactions leading to a higher rise in total output compared with the initial increase in $\Delta Y$ tourism expenditure. The model allows the calculation of two types of multipliers in tourism. Indirect effects of tourism can be obtained by dividing total output with the incremental increase of tourism expenditure, while the induced 
Table 1: Assumptions of Input-Output Model

\begin{tabular}{|l|l|}
\hline Assumption & Explanation \\
\hline \multirow{2}{*}{ Constant Return to Scale } & $\begin{array}{l}\text { The same amount of inputs is required to produce one more unit following the } \\
\text { increased expenditure. In reality more or fewer inputs might be required } \\
\text { to produce each additional unit }\end{array}$ \\
\hline Nonexistence of Supply Constraints & $\begin{array}{l}\text { The required input to produce any amount of additional output of } \\
\text { an industry is assumed to be always available. In the real world, } \\
\text { there might be a shortage in some inputs affecting prices and } \\
\text { inter-industry relationships throughout the economy }\end{array}$ \\
\hline \multirow{2}{*}{ Fixed Input Structure } & $\begin{array}{l}\text { The industry maintains a fixed input structure despite the changes } \\
\text { in prices. In reality, producers are often substituting inputs } \\
\text { reflecting prices. }\end{array}$ \\
\hline & $\begin{array}{l}\text { The proportion of the goods produced by the industry remains } \\
\text { fixed. In reality, industries change their product mixes constantly } \\
\text { due to changes in prices, costs and other economic variables }\end{array}$ \\
\hline
\end{tabular}

effect is the ratio of the output resulting from the household's expenditures to the initial household expenditure.

I-O Model as other models uses assumptions. Assumption causes some restrictions for the model translating it into boundaries (Loomis \& Walsh, 1997). Analyzing model limitations is important for the policy-forming process and understanding the results. The limitations include constant returns to scale, no supply constraints, fixed input structure and homogenous sectorial output. The net effect of all these nonrealistic assumptions is the overestimation of results during the large external shocks. However, with moderate shock, multiplier estimates seem to be reasonable for most countries. It should also be mentioned that the I-O model does not provide many details on producers and consumers.

The first attempt to build an input-output model for Georgia was made by the author (Bregadze, 2019), however, given the insufficient methodology and limited data availability from the statistical office of Georgia the obtained results lack reliability. Since then NACE 2 and SNA 2008 were introduced with several beneficial methodological changes, leading to more precise results with the updated data set.

The Social Accounting Matrix (SAM) extends I-O modeling, showing more transactions in the national economy in greater detail. The description of the I-O model gives comparably small information regarding the role of the people and social institutions in the economy. As a result, researchers extended the I-O model by giving more details on the labor force, households, human capital, social welfare issues, which led to the introduction of the Social Accounting Matrix. The well-structured SAM can measure secondary effects by transactions, employment, and income for different households, producers, and products purchased by visitors. Multipliers are the same as in the case of the I-O model, but with more details in supply and demand. This expands the information available to policymakers about who losses the most from decreased visitor spending, prospective public policies, or other shocks (Commission, 2003).

The social accounting matrix has boundaries as well. It is the extension of the I-O model as a result inherits its four boundaries. Besides, required input data, matrix structure, and characteristics of the outputs are not standardized. Re- searchers working on SAM have more freedom to decide which information will be included in the model and how the relationship will be specified between the models. This is the reason why it is difficult to compare the data between the countries. Furthermore, informational requirements for the SAM model are much larger compared with I-O Model. Authors assume that household surveys necessary for the model are not updated regularly because of the high cost. It is not surprising that models are used just by a few countries. Finally, SAM does not require clearance of all the markets for this the next model is employed.

Alternatively, some authors advocate the use of CGE modeling arguing I-O Model and SAM have serious limitations affecting the accuracy of the estimates. (Briassoulis, 1991; Dwyer et al., 2004; Dwyer et al., 2005). Although the CGE model corrected limitations of the input-output model, some of its qualities complicate its introduction:

- The model requires massive statistical data from different sectors to describe a relation between them for a year. This data needs an annual update to describe the changes regularly. This process is costly, that's why it is a common practice among researchers to estimate the model for one year and use it for the subsequent years. This method results in inaccuracy because interrelations between sectors may change during the years and as a result model will describe the reality of the past, instead of the present (Gillespie et al., 1999);

- Some assumptions made in the model is debatable, as the structural details (value of parameters, equation forms, used data) is not published, making it difficult for model users to test the actual assumptions of the model (Lapping, 2006);

- CGE models lack validations, as the results obtained from the model are seldom analyzed against the actual world. It is common practice to develop the model for the year, input exogenous variables there (e.g. tourism expenditure), and then adjust equations so that the income and output results of each sector equals country totals for that year. Then 
the assumption is made that the equations do not change for years to come (Gillespie et al., 1999). The resulting changes in GDP and employment from a policy are never compared with the forecasted value from the model (Kirkup \& Major, 2006).

The overview showed the input-output model differs from other models as it requires the least data and methodology is described precisely in various handbooks. With these qualities, it's the best candidate for the measuring secondary effects of COVID 19 on Georgian Tourism.

\section{Input-Output Model as a measure of the secondary effects of COVID 19}

To build a model as a first step symmetric Supply-Use table should be derived. For this purpose, we obtained "Supply and Use tables 20191" from the statistics office of Georgia. According to (Nations, 2010), industries can be substituted for the rows in the northwest and northeast quadrants of the Use table to produce an input-output table. For this, we made a fixed product sales structure assumption, which leads to the following mathematical derivations on the Supply Use tables (Eurostat, 2008).

$$
T=V * \operatorname{inv}[\operatorname{diag}(q)] \quad B=T * U
$$

Where $\mathrm{T}$ Transformation matrix, $\mathrm{V}$ Make matrix - transpose of supply matrix (industry by-product), diag(q)-diagonal matrix of product output, $U$ Use matrix for intermediates (product by industry), B Matrix for intermediates (industry by industry). Finally, the matrix expressed with only industries was derived.

The table shows all the industries of the country in the rows supplying output to every industry represented in the columns. They gave the matrix the name "interindustry matrix" because of this quality. We can transform this table into another account called the "direct requirements table." For this, we can use the formula $A=T^{*} U^{*} \operatorname{inv}[\operatorname{diag}(g)]$, where diag (g) is the diagonal matrix of industry output.

The direct requirements table shows for each purchasing industry (in the column) the inputs directly required from different supplier industries (in the rows) to produce one unit of output. Through matrix algebra manipulation (called "matrix inversion") on the direct requirements table, the "total requirements table" can be derived. For this, we can use the formula described at the beginning of this chapter. By inverting (I-A), the total requirements table is obtained, which is shown below only for the "Accommodation and food service activities" part.

We have moved from an account to a model called the Input-Output (I-O) model. This model computes, for any increase in consumption of an industry's output, the total amount of intermediate output required. The received final

Table 2: Interindustry Matrix

\begin{tabular}{|c|c|c|c|c|c|c|c|c|c|c|c|c|c|c|c|c|c|c|c|c|}
\hline & A & B & C & D & E & $\mathbf{F}$ & G & H & I & J & K & $\mathbf{L}$ & $\mathbf{M}$ & $\mathbf{N}$ & 0 & $\mathbf{P}$ & $\mathbf{Q}$ & $\mathbf{R}$ & $S$ & $T$ \\
\hline A & 1016 & 0 & 1485 & 0 & 0 & 0.6 & 33.6 & 0 & 175 & 0 & 0 & 1.3 & 1.7 & 2.1 & 0 & 8.2 & 0.9 & 46.6 & 0.2 & 0 \\
\hline B & 5.6 & 139 & 340 & 0.3 & 0.2 & 162 & 13.7 & 23.2 & 2.8 & 0.8 & 1.8 & 5.9 & 0.7 & 1.5 & 2.1 & 0.3 & 1.4 & 3.2 & 1.3 & 0 \\
\hline C & 444 & 145 & 4312 & 70.4 & 76 & 2705 & 696 & 812.2 & 693 & 88.3 & 64.7 & 97 & 105 & 54.8 & 396 & 78 & 513 & 144 & 48 & 0 \\
\hline D & 22.6 & 53 & 512 & 230 & 28 & 39.9 & 128 & 132.6 & 165 & 49.6 & 40.1 & 70 & 8.6 & 5.6 & 65.7 & 39 & 74 & 56 & 12 & 0 \\
\hline E & 9.5 & 1.3 & 22.7 & 4.8 & 4.3 & 6.7 & 13 & 6.1 & 29.1 & 2.5 & 6 & 14 & 1.5 & 1.5 & 28 & 12 & 12.8 & 8.9 & 3.3 & 0 \\
\hline $\mathbf{F}$ & 6.5 & 33 & 132 & 26.2 & 9.8 & 1286 & 58.5 & 35.7 & 88.9 & 30.5 & 16 & 60 & 23.1 & 5.8 & 17.1 & 25 & 40.1 & 34.5 & 2.4 & 0 \\
\hline G & 78.7 & 148 & 951 & 73.1 & 39 & 770 & 1978 & 1345 & 63.3 & 23.5 & 57 & 25 & 47.4 & 112 & 400 & 23 & 178 & 186 & 22 & 0 \\
\hline H & 91.7 & 36 & 589 & 38.3 & 6.1 & 177 & 842 & 1181 & 52.3 & 27.8 & 64.6 & 18 & 29.2 & 120 & 89.8 & 58 & 30.8 & 102 & 12 & 0 \\
\hline 1 & 4.7 & 3.3 & 35.7 & 4.5 & 1 & 29.4 & 70.2 & 97 & 43.1 & 16 & 48.9 & 4.4 & 12.8 & 86.1 & 151 & 54 & 45.1 & 71.1 & 18 & 0 \\
\hline J & 0.5 & 1.6 & 17.2 & 42.5 & 0.8 & 119 & 260 & 8.4 & 11 & 277 & 130 & 98 & 11.1 & 2.6 & 50.1 & 12 & 7.4 & 16.5 & 4.2 & 0 \\
\hline K & 125.1 & 28 & 298 & 44.7 & 12 & 237 & 222 & 137.1 & 105 & 50.8 & 12.3 & 445 & 36.2 & 26.5 & 12 & 13 & 66 & 55.4 & 6.2 & 0 \\
\hline $\mathbf{L}$ & 2.6 & 3.1 & 143 & 5.7 & 2.3 & 79.2 & 396 & 121.2 & 240 & 69.1 & 195 & 45 & 38 & 81.7 & 116 & 15 & 63.6 & 306 & 53 & 0 \\
\hline $\mathbf{M}$ & 6.5 & 3.8 & 163 & 98.5 & 2.3 & 78.9 & 126 & 72.6 & 30.4 & 39 & 149 & 25 & 173 & 8.6 & 66.2 & 8.3 & 24.8 & 65.4 & 14 & 0 \\
\hline $\mathbf{N}$ & 1 & 2.6 & 36.3 & 19.6 & 1.8 & 30.9 & 45.1 & 39.5 & 46.7 & 42.6 & 35.4 & 71 & 22.5 & 39.3 & 42 & 14 & 33.5 & 51.4 & 5.3 & 0 \\
\hline 0 & 0 & 0 & 0.4 & 0.2 & 0 & 0 & 7.8 & 1.5 & 0.1 & 0 & 3.4 & 0 & 0 & 3.3 & 3.8 & 0.2 & 0 & 0.3 & 0 & 0 \\
\hline $\mathbf{P}$ & 0.1 & 0 & 1.8 & 0.5 & 0 & 1.4 & 1.2 & 1.2 & 0.8 & 5.2 & 9 & 0.7 & 2.7 & 0.3 & 4.6 & 24 & 25.2 & 0.9 & 0.6 & 0 \\
\hline $\mathbf{Q}$ & 0.4 & 5.9 & 7.2 & 1.6 & 0.2 & 6.3 & 10.7 & 9.6 & 6.7 & 0.3 & 0.8 & 0.3 & 2.1 & 0.8 & 35.5 & 6.6 & 168 & 2.6 & 0.2 & 0 \\
\hline $\mathbf{R}$ & 0 & 0 & 0.7 & 0.2 & 0 & 0.9 & 1 & 0.4 & 0.9 & 26.5 & 2.3 & 4.7 & 0.8 & 1 & 26.7 & 5.2 & 0.3 & 131 & 0.7 & 0 \\
\hline S & 0.4 & 0.6 & 3.4 & 17.7 & 0.4 & 1.7 & 27.5 & 2.6 & 11.3 & 14.2 & 28.1 & 1.1 & 10.3 & 0.4 & 0.6 & 2 & 4.1 & 6.2 & 34 & 0 \\
\hline $\mathbf{T}$ & 0 & 0 & 0 & 0 & 0 & 0 & 0 & 0 & 0 & 0 & 0 & 0 & 0 & 0 & 0 & 0 & 0 & 0 & 0 & 0 \\
\hline
\end{tabular}

Source: National Statistics Office of Georgia

${ }^{1}$ Retrieved from www.geostat.ge. 2021 August. 
Table 3: Direct Requirement Table

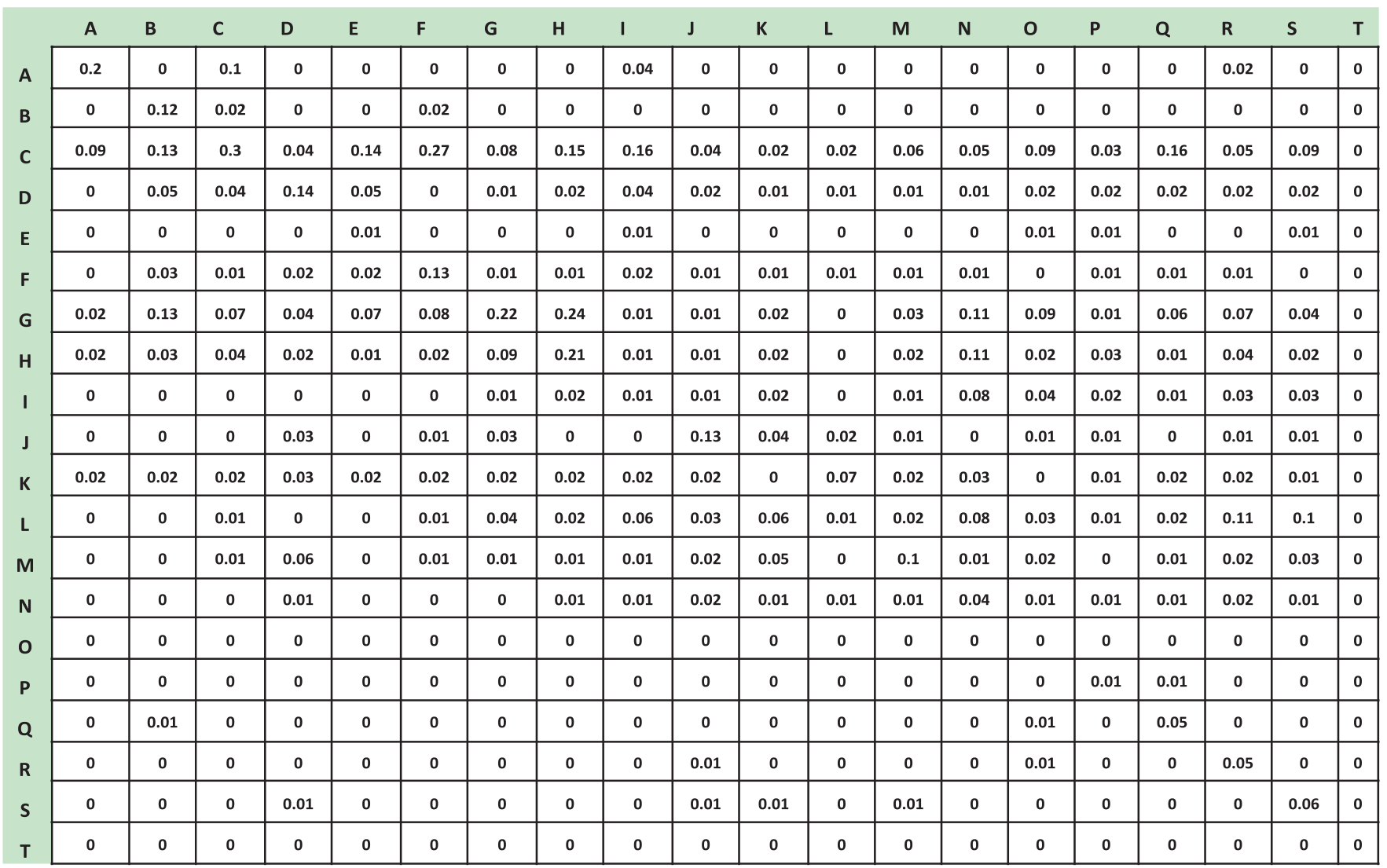

Source: National Statistics Office of Georgia

result $\Delta \mathrm{X}=(\mathrm{I}-\mathrm{A})^{-1} \Delta \mathrm{Y}$ means that if tourist expenditure increases in the country, because of inter-industry transactions expressed by the Leontief matrix, each industry's output increases more than the initial increase. This is the concept of multiplier discussed above. If the expenditure on accommodation in Georgia increases by $100 \mathrm{GEL}$, this will generate an additional $81 \mathrm{GEL}$. The sum of the output which satisfies demand is called the indirect effect of tourism, while the multiplier equals 1.81 .

To get induced effects, the household column should be added to the direct requirement table. By inserting households in the table, we treat it as a sector that requires resources (personal consumption goods) to supply labor services. After inverting the expanded direct requirement matrix, we obtain the total requirement table that now includes household consumption. Additional tourist expenditure will generate additional income for the households, which will trigger personal consumption and create an additional effect on the output. This is an induced effect. Because of the limited data availability, this variable cannot be measured in Georgia by now.

The input-output model can be a very useful tool for policymakers during the COVID-19 crisis, as it measures additional effects of tourism and captures the affected industries that would stay unmeasured otherwise:

- The model identifies the multiplier effect of tourism expenditure, which for Covid analysis translates into additional losses incurred from the ceased tourism expenditure on Accommodation and food service activities. In numerical terms, the total expenditure of 3,9 billion GEL on Accommodation and food service activities would translate into 7.1 billion GEL in a loss;

- It displays linkages between tourism industries producing for tourism demand and the industries supplying intermediate goods and services to those industries. This information can be useful to identify the major losers among suppliers. The strength of inter-industry relations is the important factor that will show how the decrease in tourism expenditure will influence other sectors beyond tourism;

- The model has potential in the future with more information available from Geostat, to identify the share of imported intermediate products. Although in peaceful times high import share would suggest the high leakage and smaller multiplier effect, in Covid times that means the lower negative effect on the local economy as the major losers, in that case, would be from outside the country. The import dependency of Georgia in tourism seems to decrease the negative effect of COVID-19 on the local economy;

- The model can be useful during the post-Covid times, as it shows estimates of the output, income, and employment multipliers for tourism expenditure, which can be compared to other types of consumer expenditure, such as investment in Agriculture. This 
Table 4: Total Requirement Table

\begin{tabular}{|c|c|c|c|c|c|c|c|c|c|c|c|c|c|c|c|c|c|c|c|c|}
\hline & A & B & C & D & $E$ & $F$ & G & $\mathrm{H}$ & 1 & & K & $\mathrm{L}$ & $M$ & $\mathbf{N}$ & 0 & $P$ & $Q$ & $\mathbf{R}$ & $S$ & $T$ \\
\hline A & & & & & & & & & 0.09 & & & & & & & & & & & \\
\hline B & & & & & & & & & 0.01 & & & & & & & & & & & \\
\hline C & & & & & & & & & 0.29 & & & & & & & & & & & \\
\hline D & & & & & & & & & 0.06 & & & & & & & & & & & \\
\hline$E$ & & & & & & & & & 0.01 & & & & & & & & & & & \\
\hline$F$ & & & & & & & & & 0.03 & & & & & & & & & & & \\
\hline G & & & & & & & & & 0.08 & & & & & & & & & & & \\
\hline $\mathrm{H}$ & & & & & & & & & 0.05 & & & & & & & & & & & \\
\hline 1 & 0 & 0.01 & \begin{tabular}{|l|}
0.01 \\
\end{tabular} & 0.01 & 0.01 & 0.01 & 0.02 & 0.03 & 1.02 & 0.01 & 0.02 & 0 & \begin{tabular}{|l|}
0.01 \\
\end{tabular} & 0.09 & 0.04 & $\begin{array}{l}0.03 \\
\end{array}$ & 0.02 & 0.04 & 0.04 & 0 \\
\hline J & & & & & & & & & 0.01 & & & & & & & & & & & \\
\hline K & & & & & & & & & 0.05 & & & & & & & & & & & \\
\hline L & & & & & & & & & 0.07 & & & & & & & & & & & \\
\hline$M$ & & & & & & & & & 0.02 & & & & & & & & & & & \\
\hline$N$ & & & & & & & & & 0.02 & & & & & & & & & & & \\
\hline 0 & & & & & & & & & 0 & & & & & & & & & & & \\
\hline$P$ & & & & & & & & & 0 & & & & & & & & & & & \\
\hline$Q$ & & & & & & & & & 0 & & & & & & & & & & & \\
\hline$R$ & & & & & & & & & 0 & & & & & & & & & & & \\
\hline s & & & & & & & & & 0 & & & & & & & & & & & \\
\hline T & & & & & & & & & 0 & & & & & & & & & & & \\
\hline
\end{tabular}

Source: National Statistics Office of Georgia

assists policymakers in determining the total effects of public policies to expand tourism expenditure compared to alternative economic development programs. If a country finds, for example, that the accommodations industry is purchasing many of its intermediate products from abroad (say, furniture and equipment), it can increase the macroeconomic contribution of serving accommodations demand by encouraging domestic enterprises to produce these items. This will reduce the leakages of demand to industries in other countries and increase the multiplier impact of tourism expenditure.

The input-output model can be further improved. For this, Geostat should publish the official valid symmetric supply-use tables and separate use table of imports and domestic production. The analytical tools are the guarantee for informed and valid decision-making that leads to effective results.

\section{CONCLUSION}

The paper showed macroeconomic analysis tools to be equally useful for policymakers during peaceful and crisis times. In peaceful times, it is a powerful tool to understand all the channels through which tourism affects the economy and stimulate its beneficial effects on employment, international currency flow, additional income source, etc. The benefits of proposed methods and models change in the crisis period as interest shifts toward estimation of a total loss to the economy, identification of most affected and vulnerable tourism fields to create relevant aid packages. Tourism statistics in general and TSA and the input-output model, in particular, can address informational requirements by delivering the relevant tourism statistics indicators.

The paper showed, that the economic impact of COVID-19 depends on five indicators: the size of internal expenditure, the share of domestic expenditure in internal expenditure, the share of internal expenditure in total output, the share of imported intermediaries, and the strength of inter-industry relations. To measure the indirect effects because of comparably low data needs, the input-output model was employed. It showed the multiplier effect of 1.81 for Accommodation and food service activities. As Georgia depends on imported goods, the multiplier effect should be lower. Although in peaceful times import dependency is not good news for the economy, in times of COVID-19 that would mitigate its negative effects. The paper suggested necessary recommendations for methodological improvements to validate results and receive the full picture. In the future, macroeconomic analysis can be extended by employing other macroeconomic tools such as SAM, CGE. 


\section{REFERENCES:}

Archer, B. H. (1982). The value of multipliers and their policy implications. Tourism Management, 3(4), 236-241. https://doi. org/10.1016/0261-5177(82)90044-9

Bregadze, G. (2019). Priorities of Formation of Tourism Development Economic Policy. Tbilisi State University.

Bregadze, G. (2021). Toward The Introduction of Tourism Satellite Account-Case Study Georgia. Globalization and Business, 11, 127-132. https://doi.org/10.35945/gb.2021.11.018

Briassoulis, H. (1991). Methodological issues: Tourism input-output analysis. Annals of Tourism Research, 18(3), 485-495. https://doi.org/10.1016/0160-7383(91)90054-F

Commission, E. (2003). Handbook on Social Accounting Matrices and Labour Accounts. In L. g. L. o. S. A. M. u. t. c.-o. o. S. Netherlands (Ed.).

Dwyer, L., Forsyth, P., \& Spurr, R. (2004). Evaluating Tourism's Economic Effects: New and Old Approaches. Tourism Management, 25, 307-317. https://doi.org/10.1016/S0261-5177(03)00131-6

Dwyer, L., Forsyth, P., \& Spurr, R. (2005). Estimating the Impacts of Special Events on an Economy. Journal of Travel Research, 43(4), 351-359. https://doi.org/10.1177/0047287505274648

Eurostat. (2008). Eurostat Manual of Supply, Use and Input-Output Tables.

Gillespie, G., Mcgregor, P., Swales, J., \& Yin, Y. (1999). A Computable General Equilibrium Approach to the Ex Post Evaluation of Regional Development Agency Policies.

Kirkup, N., \& Major, B. (2006). Doctoral Foundation Paper: The Reliability of Economic Impact Studies of the Olympic Games: A Post-Games Study of Sydney 2000 and Considerations for London 2012. Journal of Sport \& Tourism, 11, 275-296. https:// doi.org/10.1080/14775080701400943

Lapping, M. B. (2006). Community Economics: Linking Theory and Practice, edited by Ron Shaffer, Steve Deller, and Dave Marcouiller. Journal of Regional Science, 46(4), 805-806.

Loomis, J. B., \& Walsh, R. G. (1997). Recreation Economic Decisions: Comparing Benefits and Costs. Venture Pub. https:// books.google.ge/books?id=M2NmQgAACAAJ

Nations, U.(2010).System of National Accounts 2008. United Nations. https://www.un-ilibrary.org/content/books/9789210544603 Reece, W. S. (2010). The economics of tourism / William S. Reece. In The economics of tourism. Prentice Hall.

UNWTO. (2021). Conceptual Guidance on Tourism Statistics in the COVID-19 Context. https://www.e-unwto.org/doi/ epdf/10.18111/9789284422432

WTO. (1994). Políticas de Aviación y de Turismo (Versión española). World Tourism Organization. 